\title{
Utilização do Farelo de Girassol na Alimentação de Frangos de Corte ${ }^{1}$ Antonio Claudio Furlan², Cristiane Mantovani ${ }^{3}$, Alice Eiko Murakami ${ }^{2}$, Ivan Moreira ${ }^{2}$, Claudio Scapinello ${ }^{2}$, Elias Nunes Martins ${ }^{2}$
}

RESUMO - O experimento foi realizado com o objetivo de verificar o desempenho dos frangos de corte alimentados com rações contendo níveis crescentes de farelo de girassol. Foram utilizados 1200 pintos de um dia de idade, distribuídos em um delineamento experimental inteiramente casualizado com seis tratamentos, quatro repetições e 50 aves por unidade experimental. Os tratamentos consistiram de uma ração testemunha (RT) à base de milho e farelo de soja e outras cinco com 10, 20, 30, 40 e 50\% de substituição da proteína do farelo de soja pela proteína do farelo de girassol. Observou-se efeito quadrático dos níveis crescentes do farelo de girassol sobre a conversão alimentar, na fase inicial, no consumo de ração e no ganho médio de peso, na fase de crescimento, e no ganho de peso, no período total. Em rações isoenergéticas e isoaminoacídicas para metionina+cistina e lisina digestíveis, a proteína do farelo de soja pode ser substituída pela proteína do farelo de girassol até o nível de 30\%, o que corresponde a cerca de $15 \%$ de inclusão de farelo de girassol nas rações dos frangos de corte.

Palavras-chave: desempenho, farelo de girassol, frangos de corte

\section{Use of Sunflower Meal in Broiler Chicks Feeding}

ABSTRACT - A trial was carried out to evaluate the broiler chicks performance fed with increasing sunflower meal levels. A total of 1200 one-day-old chicks were allotted in a completely randomized design with six treatments, four replicates and 50 birds by experimental unit. The treatments consisted on a corn, soybean meal based control diet (RT) and five others with 10, 20, 30, 40 and $50 \%$ of soybean meal protein replacement by sunflower meal protein. A quadratic effect of the sunflower meal levels on feed gain at initial phase, on feed intake and average weight gain at growing phase and on weight gain at total period were observed. In isoenergetic and isoaminoacid diets for digestible methionine+cystine and lysine, the soybean meal protein can be replaced by the sunflower meal protein up to $30 \%$ level, which corresponds to nearly $15 \%$ of sunflower meal inclusion in the broiler chicks diets.

Key Words: performance, sunflower meal, broiler chicks

\section{Introdução}

O farelo de girassol, subproduto da extração do óleo, possui elevados teores de proteína bruta, o que permite o seu uso em rações como fonte de proteína e aminoácidos. WALDROUP et al. (1970) concluíram ser possível a inclusão do farelo de girassol nas rações sem suplementação de lisina até $20 \%$. COSTA (1974) também não verificou prejuízos no ganho de peso e na conversão alimentar até o nível de $20 \%$ de inclusão do farelo de girassol, sem a suplementação de lisina, o que concorda com VALDIVE (1982) e ZATARI e SELL (1990a). IBRAHIM e EL ZUBEIR (1991), contudo verificaram que o farelo de girassol pode ser utilizado nas rações até o nível de $30 \%$.

Os resultados de desempenho obtidos com frangos em crescimento, obtidos por RAD e KESHAVARZ (1976), indicaram que o farelo de girassol pode substituir até $50 \%$ da proteína bruta do farelo de soja, o que correspondeu a $17,5 \%$ de inclusão, sem causar prejuízo no desempenho, entretanto, o nível de $100 \%$ de substituição poderia ser atingido, desde que houvesse suplementação de lisina e de uma fonte rica em energia.

A inclusão de até $10 \%$ de farelo de girassol com $32,6 \% \mathrm{~PB}$ e $18,4 \% \mathrm{FB}$, suplementado com gordura e lisina, não prejudicou o ganho de peso e a conversão alimentar dos frangos com sete semanas de idade (ZATARI e SELL, 1990b).

MUSHARAF (1991), utilizando farelo de girassol com $31,2 \%$ de $\mathrm{PB}$ e $20,6 \%$ de $\mathrm{FB}$, para frangos de 1 a 6 semanas, suplementado com lisina e metionina, verificou que, mesmo utilizando farelo com alto conteúdo de fibra, o farelo poderia ser incluído em até

\footnotetext{
${ }^{1}$ Parte da dissertação de mestrado apresentada pela segunda autora.

${ }^{2}$ Professor do Departamento de Zootecnia da UEM-Maringá-PR. E.mail: acfurlan@uem.br; aemurakami@uem.br; imoreira@uem.br; cscapinello@uem.br; enmartins@uem.br

3 Pós-Graduanda do Programa de Pós-Graduação em Zootecnia da UEM-Maringá-PR - Bolsista CAPES.
} 
$25 \%$ nas rações, sem prejudicar o desempenho dos mesmos. WALDROUP (1970) também observou que a suplementação de lisina em rações peletizadas permitiu a inclusão de até $30 \%$ de farelo de girassol às rações.

Entretanto, em função de diferenças entre cultivares, do solo e do processamento adotado (KARUNOJEEWA et al., 1989 e PELEGRINI, 1989), ocorre variação na composição química do farelo obtido, principalmente no conteúdo de fibra e, conseqüentemente, nos percentuais de utilização nas rações (ZATARI e SELL, 1990a). Isso ocorre porque a fibra em alta concentração diminui a energia metabolizável das rações e o aproveitamento dos nutrientes e, conseqüientemente, acarreta redução na taxa de crescimento e piora na eficiência alimentar (CAFÉ, 1993 e BEDFORD, 1995).

Verifica-se, portanto, que os níveis de inclusão recomendados são variáveis e dependentes, principalmente, da composição química e valor energético do farelo de girassol avaliado.

Assim, o objetivo deste trabalho foi verificar o desempenho dos frangos de corte alimentados com rações contendo níveis crescentes de farelo de girassol.

\section{Material e Métodos}

O experimento foi conduzido no Aviário da Fazenda Experimental de Iguatemi (FEI) da Universidade Estadual de Maringá, no período de 07 de abril a 18 de maio de 1998.

Foram utilizados 1200 pintos de 1 dia de idade, machos, da linhagem Cobb. As aves foram alojadas em um galpão convencional, dividido em boxes de $6,3 \mathrm{~m}^{2}$, com cobertura de telha francesa e lanternin, piso de concreto e paredes laterais de alvenaria, com $0,30 \mathrm{~m}$ de altura e o restante com tela de arame até o telhado, providas de cortinas laterais. Foi colocada cama do tipo maravalha sobre o piso.

Em cada box foram utilizados um círculo de proteção e uma campânula como fonte de aquecimento para os pintos. No sétimo dia de idade, as aves foram vacinadas contra as doenças Newcastle e Gumboro via ocular.

$\mathrm{Na}$ fase inicial, foram utilizados comedouros do tipo bandeja de $0,50 \times 0,40 \times 0,05 \mathrm{~m}$ e bebedouros do tipo copo de pressão até o quinto dia de idade, que foram substituídos pelo comedouro tubular e bebedouro automático do tipo pendular.

Água e ração foram fornecidas à vontade em um programa de alimentação, dividido em duas fases: a inicial, do $1 \cong$ aos 21 odia de idade, e a de crescimento, do $22 \circ$ ao $42 \circ$ dia de idade.

As rações foram calculadas com base nas exigências nutricionais de ROSTAGNO et al. (1996), na composição química dos alimentos, de acordo com ROSTAGNO et al. (1994), e nas análises químicas realizadas no Laboratório de Nutrição Animal da UEM/DZO. As rações experimentais foram isocalóricas, isoaminoacídicas para metionina + cistina e lisina digestíveis, isocálcicas e isofosfóricas (Tabelas 1e 2).

Os tratamentos consistiram de uma ração testemunha sem farelo de girassol e os demais, da substituição da proteína do farelo de soja pela proteína do farelo de girassol nos níveis de 10, 20, 30, 40 e 50\%. $\mathrm{O}$ farelo de girassol avaliado apresentou 92,68\% MS, $34,07 \%$ PB, 21,73\% FB, $0,45 \%$ Ca, $1,13 \%$ Pe 1,40\% EE.

Para verificar a viabilidade econômica da substituição da proteína do farelo de soja pela proteína do farelo de girassol nas rações, determinou-se inicialmente o custo da ração por quilograma de peso vivo ganho (Yi), segundo BELLAVER et al. (1985).

$$
\mathbf{Y}_{i}=\frac{\mathbf{Q}_{i} \mathbf{x} \mathbf{P}_{i}}{\mathbf{G}_{i}}
$$

em que $Y_{i}$ é custo da ração por quilograma de peso vivo ganho no i-ésimo tratamento; $\mathrm{P}_{\mathrm{i}}$, preço por quilograma da ração utilizada no i-ésimo tratamento; $\mathrm{Q}_{\mathrm{i}}$, quantidade de ração consumida no i-ésimo tratamento; e $\mathrm{G}_{\mathrm{i}}$, ganho de peso do i-ésimo tratamento.

Em seguida, foram calculados o Índice de Eficiência Econômica (IEE) e o Índice de Custo (IC), propostos por FIALHO et al. (1992).

$$
\mathbf{I E E}=\frac{\mathrm{MC} e}{\mathbf{C T} e i} \times 100 \text { e IC }=\frac{\mathbf{C T} e i}{\mathrm{Mc} e i} \times 100
$$

em que MCe é o menor custo da ração por quilograma ganho observado entre os tratamentos e $\mathrm{CT}_{\text {ei }}$, custo do tratamento i considerado.

As rações e os animais foram pesados a cada troca de rações, com o objetivo de calcular o ganho de peso, consumo de ração e conversão alimentar.

O delineamento experimental utilizado foi inteiramente casualizado, com seis tratamentos, quatro repetições e 50 aves por unidade experimental.

Os dados foram analisados de acordo com o seguinte modelo estatístico:

$$
\mathrm{Y}_{\mathrm{ij}}=\mu+\mathrm{N}_{\mathrm{i}}+\mathrm{e}_{\mathrm{ij}}
$$

em que $Y_{i j}$ é valor observado das variáveis estudadas relativas à unidade experimental $\mathrm{j}$, recebendo o nível de substituição i de farelo de girassol; $\mu$, constante 
Tabela 1 - Composição percentual e química da ração testemunha e das rações experimentais (na base $\mathrm{MN}$ ) Table 1 - Percentage and chemical composition of the control diet and exper,mental diets (as fed basis)

\begin{tabular}{|c|c|c|c|c|c|c|}
\hline \multirow{3}{*}{$\begin{array}{l}\text { Ingredientes }(\%) \\
\text { Ingredients }\end{array}$} & \multirow{3}{*}{$\begin{array}{l}\text { Testemunha } \\
\text { Control }\end{array}$} & \multicolumn{5}{|c|}{$\begin{array}{l}\text { Inicial } \\
\text { Initial }\end{array}$} \\
\hline & & \multicolumn{5}{|c|}{$\begin{array}{c}\text { Níveis de substituição da PB (\%) } \\
\text { Substitution levels of } C P(\%)\end{array}$} \\
\hline & & 10 & 20 & 30 & 40 & 50 \\
\hline Milho & 55,56 & 53,22 & 50,96 & 48,67 & 46,36 & 44,09 \\
\hline $\begin{array}{l}\text { Corn } \\
\text { Farelo de soja }\end{array}$ & 37,67 & 33,93 & 30,15 & 26,38 & 22,62 & 18,85 \\
\hline $\begin{array}{l}\text { Farelo de girassol } \\
\text { Sunflower meal }\end{array}$ & - & 5,05 & 10,09 & 15,14 & 20,18 & 25,23 \\
\hline \multicolumn{7}{|l|}{ Soybean oil } \\
\hline $\begin{array}{l}\mathrm{L} \text {-lisina } \mathrm{HCl} 78,5 \% \\
\mathrm{HCl} \text { L-lysine } 78.5 \%\end{array}$ & - & 0,06 & 0,12 & 0,18 & 0,25 & 0,30 \\
\hline \multicolumn{6}{|l|}{ DL-methionine $99 \%$} & 0,17 \\
\hline $\begin{array}{l}\text { Fosfato bicálcico } \\
\text { Dicalcium phosphate }\end{array}$ & 1,81 & 1,76 & 1,70 & 1,65 & 1,60 & 1,54 \\
\hline $\begin{array}{l}\text { Calcário } \\
\text { Limestone }\end{array}$ & \multicolumn{5}{|c|}{ Limestone } & 1,17 \\
\hline \multicolumn{6}{|l|}{ Salt } & 0,40 \\
\hline $\begin{array}{l}\text { Supl. Min. + Vit. }{ }^{1} \\
\text { Mineral-Vitamin supl. }\end{array}$ & 0,60 & 0,60 & 0,60 & 0,60 & 0,60 & 0,60 \\
\hline $\begin{array}{l}\text { Antioxidante }(\mathrm{BHT}) \\
\text { Antioxidant }(B H T)\end{array}$ & \multicolumn{6}{|c|}{$\begin{array}{l}\text { Valores calculados } \\
\text { Calculated values }^{2}\end{array}$} \\
\hline \multicolumn{7}{|l|}{ Crude protein (\%) } \\
\hline $\begin{array}{l}\mathrm{EM}(\mathrm{kcal} / \mathrm{kg}) \\
M E(k c a l / k g)\end{array}$ & 3000 & 3000 & 3000 & 3000 & 3000 & 3000 \\
\hline \multicolumn{7}{|l|}{ Crude fiber (\%) } \\
\hline \multicolumn{7}{|l|}{ Calcium (\%) } \\
\hline \multicolumn{7}{|l|}{ Available phosphorus } \\
\hline \multicolumn{7}{|l|}{ Methionine + Cystine (\%) } \\
\hline $\begin{array}{l}\text { Met }+ \text { Cis digestível }(\%) \\
\text { Digestible methionine }+ \text { cys }\end{array}$ & 0,80 & 0,80 & 0,80 & 0,80 & 0,80 & 0,80 \\
\hline $\begin{array}{l}\text { Lisina }(\%) \\
\text { Lysine (\%) }\end{array}$ & 1,21 & 1,20 & 1,20 & 1,19 & 1,19 & 1,18 \\
\hline $\begin{array}{l}\text { Lisina digestível (\%) } \\
\text { Digestible lysine (\%) }\end{array}$ & 1,06 & 1,06 & 1,06 & 1,06 & 1,06 & 1,06 \\
\hline $\begin{array}{l}1 \text { SUPREAVE - Suplemento vi } \\
\text { (Initial): Vit. A, 2.000.000 Ul; } \\
\text { acid), } 100 \mathrm{mg} \text {; Ác. nicotínic } \\
60.000 \mathrm{mg} \text {; Vit. } \mathrm{B}_{12}, 2000 \mathrm{mcg} \\
20.000 \mathrm{mg} \text {; Metionina (Methi } \\
2 \text { Valores calculados com bas } \\
2 \text { Calculated values based on RO }\end{array}$ & $\begin{array}{l}\text { mineral (Mineral } \\
.000 \mathrm{Ul} \text {; Vit. E, } 4 \text {. } \\
\text { acid), } 5.000 \mathrm{mg} \text {; } \\
10 \mathrm{mg} ; \mathrm{Cu}, 1.600 \mathrm{~m} \\
7.800 \mathrm{mg} \text {; Coccic } \\
\text { STAGNO et al. } \\
\text { tal. (1996) and perc }\end{array}$ & $\begin{array}{l}\text { in suppler } \\
\text {; Vit. K, } 5 \\
\text { (Biotine) } \\
2.000 \mathrm{mg} \\
\text { o (Coccid } \\
\text { nas cor } \\
\text { compositio }\end{array}$ & $\begin{array}{l}\text { mposiçã } \\
\text { it. } B_{1}, 24 \\
\text { Ác. pan } \\
\text { ng; Zn, } 1 \\
0.000 \mathrm{~m} \\
\text { s perce }\end{array}$ & $\begin{array}{l}\text { produto } \\
\mathrm{B}_{2}, 800 \mathrm{n} \\
\text { antotheni } \\
120 \mathrm{mg} ; \\
\text { q.s.p (Ve } \\
\text { rações. }\end{array}$ & $\begin{array}{l}\text { ion perkg } \\
400 \mathrm{~m} \\
100 \mathrm{mg} \\
; \text { Antioxic } \\
0 \mathrm{~g} .\end{array}$ & $\begin{array}{l}\text { Ict); Inicia } \\
\text { (Choline) } \\
\text { (Chtioxidant) }\end{array}$ \\
\hline
\end{tabular}


Tabela 2 - Composição percentual e química da ração testemunha e das rações experimentais (na base MN) Table 2 - Percentage and chemical composition of the control diet and experimental diets (as fed basis)

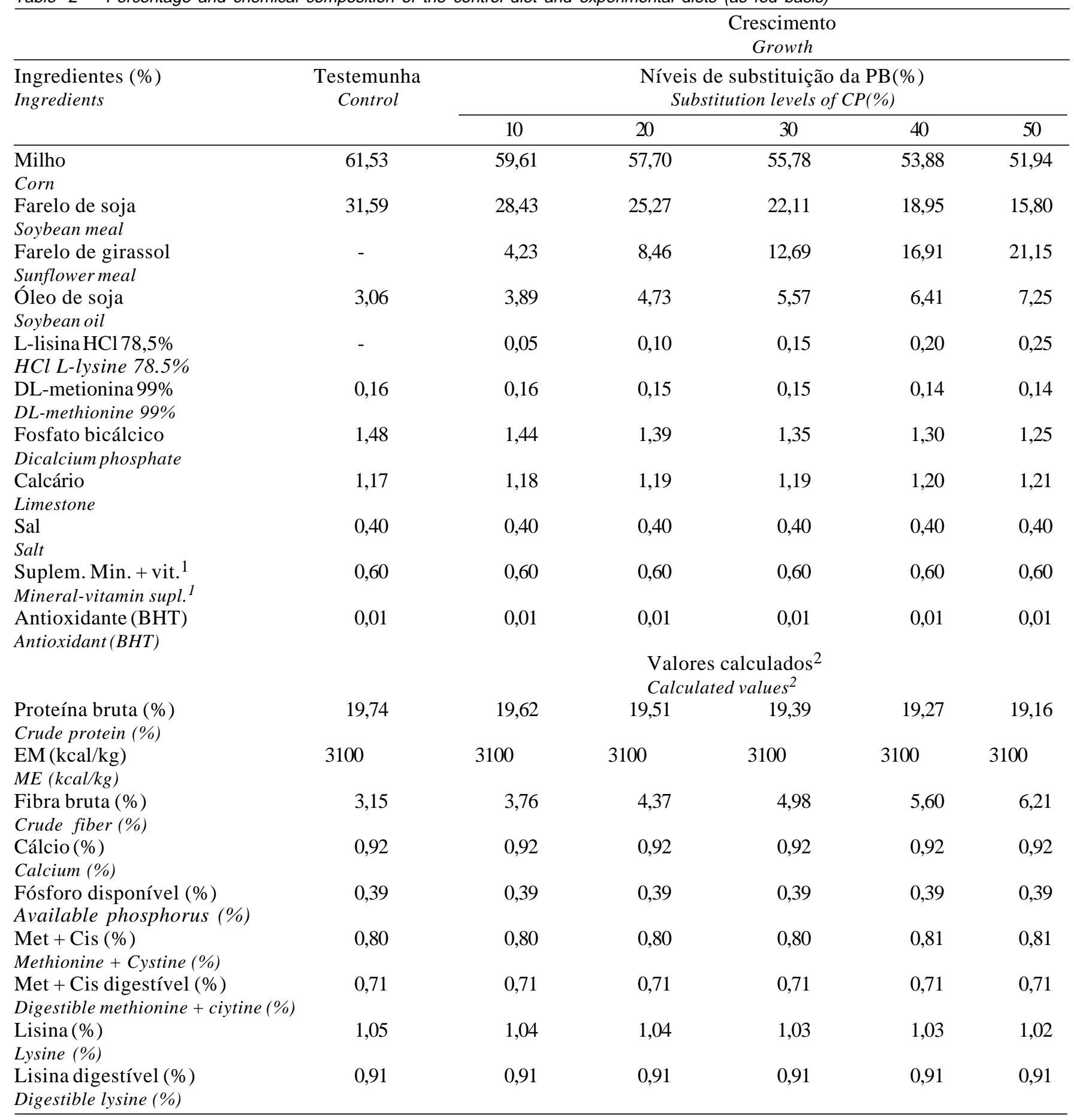

\footnotetext{
1 SUPREAVE - Suplemento vitamínico e mineral (Mineral and Vitaminic supplement); Composição por kg de produto (Composition per kg of product); Crescimento (Growth); Vit. A, 2.000.000Ul; Vit. D, 333.340 Ul; Vit. E, 3340 mg; Vit. K, 500 mg; Vit. B, 250 mg; Vit. B, 84 mg; Vit. B 417 mg; Ác. Fólico (Folic acid), 100mg; Ác. nicotínico (Nicotinic acid), $3000 \mathrm{mg}$; Biotina (Biotine), 13,5 mg; Ác. pantotênico (Pantothenic acid), $2170 \mathrm{mg}$; Colina (Choline) $50.000 \mathrm{mg} ;$ Vit. B 12 , 2084mcg; Fe, $9170 \mathrm{mg} ; \mathrm{Cu}, 1340 \mathrm{mg}$; Mn, $10.940 \mathrm{mg} ; \mathrm{Co}, 83 \mathrm{mg} ; \mathrm{Zn}, 9170 \mathrm{mg}$; I, 134mg; Se, $37 \mathrm{mg}$; Antioxidante (Antioxidant), 16.670mg; Metionina (Methionine), $255.840 \mathrm{mg}$; Coccidiostático (Coccidiostatic), $10.000 \mathrm{mg}$; Veículo (Vehicle) q.s.p., $1000 \mathrm{~g}$.

2 Valores calculados com base em ROSTAGNO et al. (1996) e nas composições percentuais das rações referência.

2 Calculated values based on ROSTAGNO et al. (1996) and percentage composition of the reference diets.
} 
162 Rev. bras. zootec.

geral; $\mathrm{N}_{\mathrm{i}}$, efeito do nível i, sendo i = 0, 10, 20, 30, 40 e 50\% (de substituição da proteína do farelo de soja pela proteína do farelo de girassol); $\mathrm{e}_{\mathrm{ij}}$, erro aleatório associado a cada observação $\mathrm{Y}_{\mathrm{ij}}$.

Os graus de liberdade referentes aos níveis de substituição, excluindo a ração testemunha, foram desdobrados em polinômios.

Para a determinação dos níveis ótimos de inclusão do farelo de girassol às rações, foi utilizado o modelo quadrático.

Para comparação dos resultados obtidos entre a ração testemunha com cada um dos níveis de substituição de farelo de girassol testados, foi utilizado o teste Dunnett a 5\%.

\section{Resultados e Discussão}

Os resultados de desempenho das aves submetidas a diferentes níveis de substituição da proteína do farelo de soja pela proteína do farelo de girassol nas rações encontram-se na Tabela 3.

$\mathrm{Na}$ análise de regressão, excluindo a ração testemunha, observou-se efeito quadrático $(\mathrm{P}<0,05)$ dos níveis de substituição da proteína do farelo de soja pela proteína do farelo de girassol sobre a conversão alimentar na fase inicial, mostrado pela equação $\hat{\mathrm{Y}}=1,5281-0,0067 \mathrm{X}+0,0001 \mathrm{X}^{2}$, compontodemínimo de $28,21 \%$, correspondendo a $14,23 \%$ de inclusão de farelo de girassol nas rações. Este nível de inclusão é inferior ao de 25\% obtido por MUSHARAF (1991), utilizando rações contendo farelo de girassol de composição química semelhante, suplementadas com metionina e lisina. RAD e KESHAVARZ (1976), mesmo sem a suplementação de lisina, observaram a possibilidade de inclusão de até $17,5 \%$ de farelo de girassol às rações.

Para a fase de crescimento, o consumo de ração e o ganho de peso também apresentaram comporta-

Tabela 3 - Consumo de ração $(\mathrm{g})$, ganho de peso $(\mathrm{g})$ e conversão alimentar nas fases inicial e de crescimento e período total Table 3 - Feed intake (g), body weight gain (G) and feed:gain ratio during the initial and growing phases and total period

\begin{tabular}{|c|c|c|c|c|c|c|c|}
\hline \multirow[t]{2}{*}{$\begin{array}{l}\text { Ingredientes }(\%) \\
\text { Ingredients }\end{array}$} & \multirow[t]{2}{*}{$\begin{array}{l}\text { Testemunha } \\
\text { Control }\end{array}$} & \multicolumn{5}{|c|}{$\begin{array}{l}\text { Níveis de substituição da } \mathrm{PB}(\%) \\
\text { Substitution levels of } C P(\%)\end{array}$} & \multirow[t]{2}{*}{$\begin{array}{l}\mathrm{CV} \\
(\%)\end{array}$} \\
\hline & & 10 & 20 & 30 & 40 & 50 & \\
\hline \multicolumn{8}{|l|}{$\begin{array}{l}\text { Fase inicial (1-21d) } \\
\text { Initial phase }\end{array}$} \\
\hline $\begin{array}{l}\text { Consumo de ração } \\
\text { Feed intake }\end{array}$ & 1126 & 1097 & 1081 & 1071 & 1126 & 1116 & 3,30 \\
\hline $\begin{array}{l}\text { Ganho de peso } \\
\text { Weight gain }\end{array}$ & 757 & $710^{*}$ & $713^{*}$ & 722 & 727 & $720 *$ & 2,51 \\
\hline $\begin{array}{l}\text { Conversão alimentar }{ }^{2} \\
\text { Feed:gain ratio }\end{array}$ & 1,488 & 1,547 & 1,515 & 1,482 & 1,549 & 1,551 & 2,71 \\
\hline \multicolumn{8}{|c|}{$\begin{array}{l}\text { Fase crescimento }(22-42 \mathrm{~d}) \\
\text { Growing phase }\end{array}$} \\
\hline $\begin{array}{l}\text { Consumo de ração }{ }^{2} \\
\text { Feed intake }\end{array}$ & 3129 & $3020 *$ & 3072 & 3112 & 3104 & $3029 *$ & 1,98 \\
\hline $\begin{array}{l}\text { Ganho de peso } \\
\text { Weight gain }\end{array}$ & 1655 & $1584 *$ & 1636 & 1627 & 1612 & $1574 *$ & 2,59 \\
\hline $\begin{array}{l}\text { Conversão alimentar } \\
\text { Feed:gain ratio }\end{array}$ & 1,890 & 1,907 & 1,878 & 1,913 & 1,926 & 1,925 & 1,59 \\
\hline \multicolumn{8}{|l|}{$\begin{array}{l}\text { Período total }(1-42 \mathrm{~d}) \\
\text { Total period }\end{array}$} \\
\hline $\begin{array}{l}\text { Consumo de ração } \\
\text { Feed intake }\end{array}$ & 4258 & 4117 & 4153 & 4183 & 4229 & 4144 & 2,01 \\
\hline $\begin{array}{l}\text { Ganho de peso } \\
\text { Weight gain }\end{array}$ & 2412 & $2293 *$ & 2349 & 2350 & 2339 & $2294 *$ & 2,30 \\
\hline $\begin{array}{l}\text { Conversão alimentar } \\
\text { Feed:gain ratio }\end{array}$ & 1,764 & 1,795 & 1,768 & 1,780 & 1,809 & 1,808 & 1,53 \\
\hline
\end{tabular}

1 Coeficiente de variação (\%).

2 Efeito quadrático $(P<0,05)$.

* Diferem pelo teste Dunnett $(P<0,05)$.

1 Coefficient of variation (\%).

2 Quadratic effect $(P<.05)$.

* Differ by Dunnett test $(P<.05)$. 
mento quadrático $(\mathrm{P}<0,05)$, obtendo-se o pontos de máximo em 31,16 e 28,48\% de substituição, respectivamente, correspondendo a 13,17 e 12,04\% de inclusão do farelo de girassol nas rações. Para esta mesma fase, MUSHARAF (1991) obteve melhores resultados com o nível de $25 \%$ de inclusão de farelo de girassol nas rações, ou seja, valores superiores aos aqui encontrados.

Considerando o período total de crescimento dos frangos, verificou-se efeito quadrático $(\mathrm{P}<0,05)$ no ganho de peso, obtendo-se a equação $\hat{\mathrm{Y}}=2,2207+0,0091 \mathrm{X}-0,0002 \mathrm{X}^{2}$, com ponto de máximo de $29,70 \%$.

O melhor nível de inclusão do farelo de girassol nas rações, determinado no período total, foi superior ao encontrado por ZATARI e SELL (1990b) e inferior aos encontrados por RAD e KESHAVARZ (1976), IBRAHIM e EL ZUBEIR (1991) e MUSHARAF (1991).

$\mathrm{Na}$ fase de crescimento, pelo mesmo teste, o consumo de ração e o ganho de peso foram menores $(\mathrm{P}<0,05)$ para os níveis de 10 e $50 \%$ em relação à ração testemunha. Semelhante à fase inicial, os teores aumentados de fibra bruta nas rações contendo farelo de girassol prejudicou o consumo de ração e o ganho de peso.

Da mesma forma, quando se comparou o período total pelo teste Dunnett, não se detectaram diferenças $(P>0,05)$ no consumo de ração e na conversão alimentar, contudo, o ganho de peso foi menor $(\mathrm{P}<0,05)$ para os níveis de substituição de 10 e $50 \%$.

Os resultados da análise econômica encontram-se na Tabela 4. Excluindo a ração testemunha, verificou-se aumento linear $(\mathrm{P}<0,05)$ no custo da ração, à medida que ocorreu a substituição da proteína do farelo de soja pela proteína do farelo de girassol. Pelo teste Dunnett, todos os níveis de substituição diferiram $(\mathrm{P}<0,05)$ da ração testemunha, sendo esta de menor custo por $\mathrm{kg}$ produzido.

Os índices de eficiência econômica e custo foram melhores para a ração testemunha, não sendo economicamente viável a inclusão de farelo de girassol na ração.

Contudo, com base nos resultados de desempenho, verificou-se ser possível a substituição de até $30 \%$ da proteína do farelo de soja pela proteína do farelo de girassol, o que fica na dependência do preço de mercado do farelo de girassol na época de utilização.

Tabela 4 - Custo da ração (CR) por quilograma de peso vivo ganho, índice de eficiência econômica (IEE) e índice de custo (IC) Table 4 - Diet cost (DC) by kilogram of body weight gain, economic efficiency index (IEE) and cost index (CI)

\begin{tabular}{|c|c|c|c|c|c|c|}
\hline \multirow[t]{2}{*}{$\begin{array}{l}\text { Ingredientes }(\%) \\
\text { Ingredients }\end{array}$} & \multirow[t]{2}{*}{$\begin{array}{l}\text { Testemunha } \\
\text { Control }\end{array}$} & \multicolumn{5}{|c|}{$\begin{array}{c}\text { Níveis de substituição da PB (\%) } \\
\text { Substitution levels of } C P(\%)\end{array}$} \\
\hline & & 10 & 20 & 30 & 40 & 50 \\
\hline $\begin{array}{l}\mathrm{CR}(\mathrm{R} \$ / \mathrm{kg} \mathrm{PV} \text { ganho })^{1 * *} \\
D C(R \$ / \mathrm{kg} B W \text { gain })\end{array}$ & 0,41 & $0,43 *$ & $0,43^{*}$ & $0,44 *$ & $0,45^{*}$ & $0,46^{*}$ \\
\hline $\begin{array}{l}\text { IEE } \\
\text { IEE }\end{array}$ & 100 & 96 & 96 & 94 & 91 & 89 \\
\hline $\begin{array}{l}\mathrm{IC} \\
C I\end{array}$ & 100 & 104 & 104 & 107 & 111 & 112 \\
\hline
\end{tabular}

1 Custos baseados em uma relação de preços para o farelo de girasssol de $60 \%$ do valor do farelo de soja.

** Efeito linear $(P<0,05)$.

* Diferem pelo teste Dunnett $(\mathrm{P}<0,05)$.

1 Costs based on sunflower meal price in relation to soybean meal price of $60 \%$.

** Linear effect $(P<.05)$.

* Differ by Dunnett test $(P<.05)$. 


\section{Conclusões}

Em rações isoenergéticas e isoaminoacídicas para metionina+cistina e lisina digestíveis, a proteína do farelo de soja pode ser substituída pela proteína do farelo de girassol até o nível de $30 \%$, o que corresponde a cerca de $15 \%$ de inclusão de farelo de girassol nas rações.

\section{Referências Bibliográficas}

BEDFORD, M.R. 1995. Mechanism of action and potential environmental benifits from the use of feed enzy mes. Anim. Feed Sci. Technol., 53:145-155.

BELLAVER, C., FIALHO, E.T., PROTAS, J.F.S. et al. 1985. Radícula de malte na alimentação de suínos em crescimento e terminação. Pesq. Agropec. Bras., 20(8):969-974.

CAFÉ, M.B. Estudo do valor nutricional da soja integral processada para aves. Jaboticabal, UNESP, 1993.97p. Dissertação (Mestrado em Zootecnia) - Universidade Estadual Paulista, 1993.

COSTA, C.P. Influência da lisina nas dietas contendo farelo de girassol para frangos de corte. Belo Horizonte, MG: UFMG, 1974. 35p. Dissertação (Mestrado em Zootecnia) - Universidade Federal de Minas Gerais, 1974.

FIALHO, E.T., BARBOSA, O., FERREIRA, A.S. et al. 1992. Utilização da cevada suplementada com óleo de soja para suínos em crescimento e terminação. Pesq. Agropec. Bras., 27(10):1467-1475.

IBRAHIM, M.A., EL ZUBEIR, E.A. 1991. Higher fibre sunflower seed meal in broiler chick diets. Anim. Feed Sci. Technol., 33:343-347.

KARUNAJEEWA, H., THAN, S.H., ABU-SEREWA, S. 1989. Sunflower seed meal, sunflower oil and full-fat sunflower seeds, hulls and kernels for laying hens. Anim. Feed Sci. Technol., 26:45-54.

MANTOVANI, C., FURLAN, A.C., MURAKAMI, A.E. et al. Composição química e valor energético do farelo e da semente de girassol para frangos de corte. In: REUNIÃO ANUAL DA SOCIEDADE BRASILEIRA DE ZOOTECNIA, 36, 1999, Porto Alegre. Anais... Porto Alegre: SBZ, 1999. p.189.

MUSHARAF, N.A. 1991. Effect of graded levels of sunflower seed meal in broiler diets. Anim. Feed. Sci. Technol., 33(112):129-137.
PELEGRINI, B. 1989. Girassol: Uma planta solar que das américas conquistou o mundo. São Paulo: Icone. $117 \mathrm{p}$.

RAD, F.H., KESHAVARZ, K. 1976. Evaluation of the nutritional value of sunflower meal and the possibility of substitution of sunflower meal for soybean meal in poultry diets. Poult. Sci., 55:1757-1765.

ROSTAGNO, H.S., BARBARINO JR., P., BARBOSA, W.A. Exigências nutricionais das aves determinadas no Brasil. In: SIMPÓSIO INTERNACIONAL SOBRE EXIGÊNCIA NUTRICIONAIS DE AVES E SUÍNOS, 1996, Viçosa. Anais... Viçosa: UFV, 1996. 457p.

ROSTAGNO, H.S., SILVA, D.J., COSTA, P.M.A. et al. 1983. Composição de alimentos e exigências nutricionais de aves e suínos (Tabelas brasileiras). Viçosa: UFV. 59p.

SILVA, D.J. 1990. Análise de alimentos (métodos químicos e biológicos), 2.ed., Viçosa: UFV. 165p.

VALDIVE, M. 1982. The utilization of $20 \%$ sunflower seed meal in broilers diets. Cuba J. Agric. Sci., 16(4):382-388.

WALDROUP, P.W., HILLARD, C.M., MITCHELL, R.J. 1970 Sunflower meal as a protein supplement for broiler diets. Feedstuffs, 42(43):41.

ZATARI, I.M., SELL, J.L. 1990a. Effects of pelleting diets containing sunflower meal on the performance of broiler chickens. Anim. Feed Sci. Technol., 30:121-129.

ZATARI, I.M., SELL, J.L. 1990b. Sunflower meal as a component of fat-supplemented diets for broiler chickens. Poult. Sci. 69:1503-1507.

Recebido em: 14/12/99

Aceito em: 21/08/00 